\title{
Co-axial hollow fiber module for air gap membrane distillation
}

\author{
A. Alpatova ${ }^{1 \mathrm{a}}$, A.S. Alsaadi ${ }^{2 a}$, M. Alharthi ${ }^{1}$, J.-G. Lee $^{1}$, N. Ghaffour ${ }^{1 *}$ \\ ${ }^{1}$ King Abdullah University of Science and Technology (KAUST), Water Desalination and Reuse Center (WDRC), \\ Biological and Environmental Science and Engineering Division (BESE), Thuwal 23955-6900, Saudi Arabia, Tel. \\ +966-8082180,Email: noreddine.ghaffour@kaust.edu.sa \\ ${ }^{2}$ Chemical Engineering Department, University of Jeddah, Jeddah 21589, Saudi Arabia \\ ${ }^{a}$ Equally contributed to this work
}

\section{Abstract}

A novel air gap membrane distillation (AGMD) module in which non-porous polymeric hollow fiber condensers (i.e., heat exchangers) were inserted inside the porous hollow fiber membranes was developed. In this module the hot feed was circulated on the outer side of the membrane's lumen and the coolant was circulated counter-currently inside the condenser fibers. The condensation of water vapor occurred in the air gap between the inner surface of the membrane fibers and the outer surface of the condenser fibers. By varying the number of condenser fibers inside the lumen, a different ratio of membrane fiber active surface area to the total surface area of condenser fibers and corresponding packing densities were achieved and examined in desalination of Red Sea water. The effect of membrane type on process performance was investigated with three different hollow fiber membranes with varied wall thickness (two capillary and one tubular). At a feed temperature of $85^{\circ} \mathrm{C}$, the water vapor flux increased from $12 \mathrm{~kg} / \mathrm{m}^{2} \mathrm{~h}$ to $18 \mathrm{~kg} / \mathrm{m}^{2} \mathrm{~h}$ with the increase in condenser fibers packing density from $9 \%$ to $28 \%$, and then decreased to $14 \mathrm{~kg} / \mathrm{m}^{2} \mathrm{~h}$ when packing density was increased to $36 \%$ due to condensing surface constrain inside the lumen. A higher efficiency of the AGMD process was observed in the case of capillary membranes as compared to tubular membranes due to reduction in wall thickness which facilitated lower mass transfer resistance. The effect of operating conditions including feed and coolant flow rates and temperature difference between the feed and coolant solutions was also investigated. The increase in the feed flow rate had significant effect on vapor flux comparing to that of coolant for all tested AGMD configurations. This effect was more pronounced at high feed temperatures. Based on observed results, an optimal module design was suggested. 
Keywords: Hollow fiber AGMD module, Compact module, Evaporation/condensation surface area, Internal heat recovery, Thermal efficiency, Desalination.

\section{Introduction}

Due to depletion of the fossil fuel reserves, fluctuations in the oil and gas prices and adverse environmental effects caused by the emission of greenhouse gases, the global trend is shifting towards developing more energy-efficient desalination technologies [1]. In this regard, membrane distillation (MD) can be viewed as an emerging technology which offers a range of advantages comparing to other desalination techniques with respect to energy-saving and product quality parameters [2-5].

The MD process is based on transport of water vapor across a hydrophobic membrane due to transmembrane temperature difference [6]. The water-repellant properties of hydrophobic membranes restrain the water molecules in the liquid state from entering the membrane pores; the non-volatile feed constituents including salts, macromolecules, colloidal particles are also rejected $[7,8]$. The MD process does not require intensive pre-treatment of the feed water and offers better product quality comparing to sea water reverse osmosis (SWRO) [9-12]. Another advantage of $\mathrm{MD}$ is its lower heating regime as compared to conventional thermal desalination processes like multi-stage flash or multi-effect distillation $[4,13,14]$. Moreover, the reduced process footprint and ability to utilize renewable energy [15] as a heat source make MD an attractive technology for freshwater production in small coastal communities, especially in coastal areas of MENA countries where the high annual ambient temperatures are observed [16, 17].

An array of different MD arrangements including direct contact MD (DCMD), air gap MD (AGMD), vacuum MD (VMD) and sweeping gas MD (SGMD) [18] have been widely reported, and more recently other novel configurations aiming to enhance the water vapor flux, such as material gap MD [19] or flashed feed MD [20] have been investigated. Despite its simplicity and high flux, the DCMD is characterized by relatively low thermal efficiency compared to AGMD [21]. Other advantages of AGMD is possibility of using lower grade water (e.g., seawater, brine) as a coolant (to be used as feed water after harvesting the latent heat of evaporation) as well as lower pore wetting propensity [22].

Generally, the AGMD vapor flux increases with decreasing permeate gap width [23, 24]. However, our previous research showed that it is technically challenging to achieve a very small 
gap width in the flat sheet module configuration [23, 25]. From practical point of view, a small distance between the membrane and condenser surfaces could be accomplished in the hollow fiber membrane configuration. Yet, controlling a fixed air gap width is challenging due to the flexibility of fibers inside the shell. Other advantage of hollow fiber membranes is their larger membrane surface area per unit of module volume (packing density) which allows for higher production capacity, as well as simple design and good process scalability [26].

Several studies were focused on the development of hollow fiber AGMD modules. A majority of them discussed a parallel arrangement of hollow fiber membranes and heat exchangers in the module shell, which served as a condensate collector [27-30]. In one of the early studies, Cheng at al. [27] conducted a numerical simulation of such arrangement to optimize the process performance as a function of packing density. The authors concluded that increase in packing density of fibers enhances product flux due to reduction in the air gap width. However, the maximum projected flux, reported in this study at a hot feed inlet temperature of $80^{\circ} \mathrm{C}$, was below $12 \mathrm{~kg} / \mathrm{m}^{2} \mathrm{~h}$. In a follow up practical study, Singh and Sirkar [28] designed a two hollow-fiber-set AGMD module with a varying number of hollow fibers and dense heat exchangers. An improved vapor flux and thermal efficiency of up to $63 \%$ was demonstrated when two modules were combined in series in order to recover the heat from the condensate and coolant. Yao et al. [29] added an internal heat recovery function to the AGMD module consisted of packed hollow fibers in which coolant and hot feed flew counter-currently. While thermal efficiency of the process was increased to $79.9 \%$, the maximum achieved vapor flux during concentrating dilute sugar solution was below $4 \mathrm{~L} / \mathrm{m}^{2} \mathrm{~h}$ (at a feed temperature of $90^{\circ} \mathrm{C}$ ). Geng et al. [30] further improved the hollow fiber-based AGMD module performance by inserting a polypropylene net between the rows of hollow fibers and heat exchangers to fix an air gap at $0.5 \mathrm{~mm}$. However, even with this modification, the maximum vapor flux of $5.3 \mathrm{~kg} / \mathrm{m}^{2} \mathrm{~h}$ was obtained at the feed inlet feed temperature of $90^{\circ} \mathrm{C}$. Few attempts were made to improve the thermal conductivity of the process by introducing copper [31] or stainless steel [32] elements to the AGMD module. Thus, Cheng et al. [31] suggested a non-porous finned copper tube for the cold flow and the grooves outside the tube for air gap and permeate collection. In this module, a thickness of the groove which corresponded to the air gap width, varied in the range of $1 \mathrm{~mm}$ to $2.3 \mathrm{~mm}$. At a feed temperature of $75^{\circ} \mathrm{C}$, an increase in vapor flux from $16 \mathrm{~kg} / \mathrm{m}^{2} \mathrm{~h}$ to $21 \mathrm{~kg} / \mathrm{m}^{2} \mathrm{~h}$ was observed when the air gap width was reduced from $2.3 \mathrm{~mm}$ to $1 \mathrm{~mm}$. However, similarly to our previous work with flat sheet 
AGMD module [23], the authors were not able to achieve smaller air gaps due to limitations in the inner diameter of the tube and difficulties in module fabrication. In a recent study, Aryapratama et al. [32] suggested a hollow fiber AGMD module made of stainless steel and equipped with multiple cooling channels. The cooling channels comprised inner and outer channels with a network of connectors between them. By varying position of hollow fibers between the channels, the authors observed a vapor flux of $12.5 \mathrm{~kg} / \mathrm{m}^{2} \mathrm{~h}$ (feed temperature of $75^{\circ} \mathrm{C}$ ) when the membrane fibers were placed close to outer cooling wall which had larger condensation surface area. The authors suggested that in order to achieve high vapor fluxes, the AGMD module has to be optimized by reducing air gap width and increasing surface area of condensation. Although higher vapor fluxes were achieved with metals heat exchangers comparing to non-porous polymeric heat exchangers, the overall design of the modules was complicated. Moreover, the usage of expensive metal elements in module fabrication would increase capital cost of AGMD module and make it prone to corrosion and affect the overall product water quality.

Summarizing the outcome from these studies, we can conclude that there is a need to develop a new concept of AGMD module which would satisfy a set of criteria arising from our own experience in MD module fabrication and combined with the guidelines and suggestions set by other researchers. First criteria is the ability of module to achieve high vapor fluxes while maintaining good permeate quality. This will depend not only on module configuration, but also on membrane's separation properties as well as on system's operating parameters. Another criteria which is also important while designing a new AGMD module is its small footprint and improved internal heat recovery. A simple and easy design based on commercially available components, is a third criteria that will help in scaling up the process from the bench top to industry.

The objective of our study was then to develop an optimal hollow fiber AGMD module which would meet the above criteria and to comprehensively evaluate its performance in seawater desalination. As a result, we are presenting a novel AGMD module in which non-porous polymeric hollow fibers (i.e., heat exchangers for condensation; condenser fibers from now on) were enclosed inside the porous hollow membrane fibers arranged inside the module shell. The hot feed solution was circulated on the outer side of the membrane fibers and the coolant was circulated countercurrently inside the condenser fibers. The module was placed in the upright position to achieve vertical condensation of the water vapor on the outer surface of the condenser fibers (made of polypropelene (PP)). The advantage of the vertical condensation is its improved thermal-hydraulic 
125 performance including higher heat transfer coefficient as compared to that of horizontal 126 condensation (i.e. when the tube is positioned parallel to the base) [33]. The condensation process 127 inside the vertical tube has been extensively studied (e.g., [34-38]). Generally, condensation is 128 differentiated into two main processes: film condensation which occurs on hydrophilic surfaces 129 and dropwise condensation which takes place on hydrophobic surfaces with low surface energy by increasing interfacial tension so that the small adjacent condensates coalesce [39]. Since

131 dropwise condensation is more thermally efficient compared to film condensation by providing 132 significantly higher heat transfer coefficient [40], improved performance of the novel AGMD module is expected due to the hydrophobic nature of the condenser fibers. By varying the number 134 of condenser fibers inside the lumen, a different ratio of membrane active surface area 135 (evaporation) to the total surface area of condensation and corresponding packing densities were achieved and examined with respect to their effect on vapor flux. Three different hollow fiber membranes with different wall thicknesses (two capillary fibers and one tubular membrane) on process efficiency were tested. Furthermore, the optimal ratio of the shell inner surface area to the total active surface area of membrane fibers was determined. The effect of operating conditions including feed temperature and feed and coolant flow rates were also investigated.

\section{Materials and methods}

\subsection{Feed and coolant}

144 Red Sea water was used as a feed solution in all experiments. Feed water was first pre-filtered with 1450.45 um nylon cartridge filter (Whatman, Florham Park, NJ, UDA) to remove any large particles 146 which could potentially damage the membrane surface. The physico-chemical characteristics of 147 the Red Sea water are shown in Table 1. Ultrapure Milli-Q water produced by Milli-Q Academic 148 Water Purification System (Millipore, Burlington, MA, USA) was used as a coolant.

Table 1. Physico-chemical characteristics of Red Sea water.

\begin{tabular}{ll}
\hline Parameter & Concentration \\
\hline $\mathrm{Na}^{+}, \mathrm{mg} / \mathrm{L}$ & 11,460 \\
$\mathrm{Mg}^{2+}, \mathrm{mg} / \mathrm{L}$ & 1,309 \\
$\mathrm{~B}^{3+}, \mathrm{mg} / \mathrm{L}$ & 5.6 \\
$\mathrm{Ca}^{2+}, \mathrm{mg} / \mathrm{L}$ & 470 \\
$\mathrm{~K}^{+}, \mathrm{mg} / \mathrm{L}$ & 457 \\
$\mathrm{Cl}^{-}, \mathrm{mg} / \mathrm{L}$ & 19,419 \\
$\mathrm{SO}_{4}{ }^{2-}, \mathrm{mg} / \mathrm{L}$ & 2,766 \\
Dissolved organic carbon (TOC) & 2.85
\end{tabular}


$\mathrm{pH} \quad 8.15$

Conductivity, $\mathrm{mS} / \mathrm{cm} \quad 60.3$

Total dissolved solids (TDS), mg/L $\quad 40,900$

151

152

153

154

155

156

157

158

159

160

161

162

163

164

165

166

167

168

169

170

171

172

173

174

175

176

\subsection{Membranes}

Three types of hollow fiber hydrophobic PP membranes purchased from Microdyn-Nadir (Wiesbaden, Germany) and 3M (Charlotte, NC, USA) were used in our study. The specifications of tested membranes are shown in Table 2. The flexible capillary PP condenser fibers were supplied by Zena Membranes (Brno, Czech Republic). The outer diameter (OD) of the condenser fibers was $0.55 \mathrm{~mm}$.

Table 2. Specifications of tested membranes.

\begin{tabular}{llll}
\hline \multicolumn{1}{c}{ Type } & Capillary 1 & Capillary 2 & Tubular \\
\hline Vendor & Microdyn & $3 \mathrm{M}$ & Microdyn \\
Material & $\mathrm{PP}$ & $\mathrm{PP}$ & $\mathrm{PP}$ \\
Nominal pore size, $\mu \mathrm{m}$ & 0.2 & 0.2 & 0.2 \\
Internal diameter $(\mathrm{ID}), \mathrm{mm}$ & 1.8 & 1.2 & 5.5 \\
Wall thickness, $\mu \mathrm{m}$ & 400 & 300 & 800 \\
\hline
\end{tabular}

\subsection{AGMD modules}

The capillary-based AGMD modules were prepared as follows. First, a predetermined number of condenser fibers was packed into the capillary. After that fibers were packed into polyurethane tube (shell) with the internal diameter (ID) of $6.5 \mathrm{~mm}$ and $21 \mathrm{~cm}$ length. The shell ends were capped with the T-shape fitting (Cole Parmer, Vernon Hills, IL, USA) and another $5 \mathrm{~cm}$ length polyurethane tube was attached at the opposite side of the T-shape fitting. The inner space of $5 \mathrm{~cm}$ tube was sealed with epoxy resin (Devcon, Shannon, Ireland). After curing, the excessive capillary ends which were stuck out the shell were cut out carefully to avoid any damage to condensers and to ensure that the space between the capillaries and condensers was not plugged. Then, a second set of T-shape fitting equipped with another $5 \mathrm{~cm}$ tubing was attached to both ends of the module. The condenser strings were pulled through the fitting and tube, and the latter ends were sealed again. After curing, the excessive condenser strings stacking out the module ends were cut with a sharp blade. In case of tubular membrane, commercial membrane module was purchased (MICRODYN® MD 020 TP 2N, Microdyn-Nadir, Wiesbaden, Germany) and modified for AGMD process in the same manner as described above. Totally 10 modules with different number of condenser fibers (n) and membrane fibers (f) were fabricated (Table 3). 
177 Figure 1 shows a schematic of the AGMD module (a) and its cross-section (b). The module 178 was operated in a counter-current mode with respect to feed and coolant flows. The feed water 179 entered the module shell through the Port 1, flew upwards and exited the module through the Port

180 2. The coolant water was circulated inside the condenser fibers from the top to the bottom through 181 Ports 3 and 4. The air gap was achieved on the lumen side of membrane fiber in the space between 182 the inner wall of membrane fiber and outer wall(s) of condenser fiber(s). The vapor was transported 183 from the outer side of membrane fiber to the lumen side due to the difference in vapor pressure 184 between the feed and coolant liquids. The condensed vapor was flowing down the module by 185 gravity forces and was collected through Port 5 located at the bottom of the module.

186

187 Table 3. Specifications of modules.

\begin{tabular}{llllllll}
\hline Module ID & Fiber type & $\begin{array}{l}\text { Number } \\
\text { of } \\
\text { membrane } \\
\text { fibers in } \\
\text { shell (f) }\end{array}$ & $\begin{array}{l}\text { Number of } \\
\text { fiber } \\
\text { condensers } \\
\text { in lumen } \\
\text { (n) }\end{array}$ & $\begin{array}{l}\text { Packing } \\
\text { density of } \\
\text { fiber } \\
\text { condensers } \\
\text { inside } \\
\text { membrane } \\
\text { fiber (PD1), } \\
\text { \% }\end{array}$ & $\begin{array}{l}\text { Packing } \\
\text { density of } \\
\text { membrane } \\
\text { fibers in } \\
\text { shell } \\
\text { (PD2), }\end{array}$ & $\begin{array}{l}\text { Ratio of } \\
\text { membrane fiber } \\
\text { total surface } \\
\text { area/surface area } \\
\text { of fiber } \\
\text { condensers (R1), } \\
\%\end{array}$ & $\begin{array}{l}\text { Ratio of shell } \\
\text { inner surface } \\
\text { area/surface } \\
\text { area of } \\
\text { membrane } \\
\text { fibers (R2), } \\
\%\end{array}$ \\
\hline Module 1 & Capillary 1 & 2 & 1 & 9 & 32 & 3.3 & 1.8 \\
Module 2 & Capillary 1 & 2 & 2 & 19 & 32 & 1.6 & 1.8 \\
Module 3 & Capillary 1 & 2 & 3 & 28 & 32 & 1.1 & 1.8 \\
Module 4 & Capillary 1 & 2 & 4 & 38 & 32 & 0.8 & 1.8 \\
Module 5 & Capillary 1 & 1 & 3 & 28 & 16 & 1.1 & 3.6 \\
Module 6 & Capillary 1 & 3 & 3 & 28 & 48 & 1.1 & 1.2 \\
Module 7* & Capillary 1 & 2 & 3 & - & - & - & 1.2 \\
Module 8 & Capillary 2 & 5 & 1 & 24 & 36 & 2.0 & 1.2 \\
Module 9 & Tubular & 3 & 8 & 5 & 35 & 0.8 & 1.2 \\
Module 10 & Tubular & 3 & 20 & 14 & 35 & 2.0 & \\
\hline
\end{tabular}




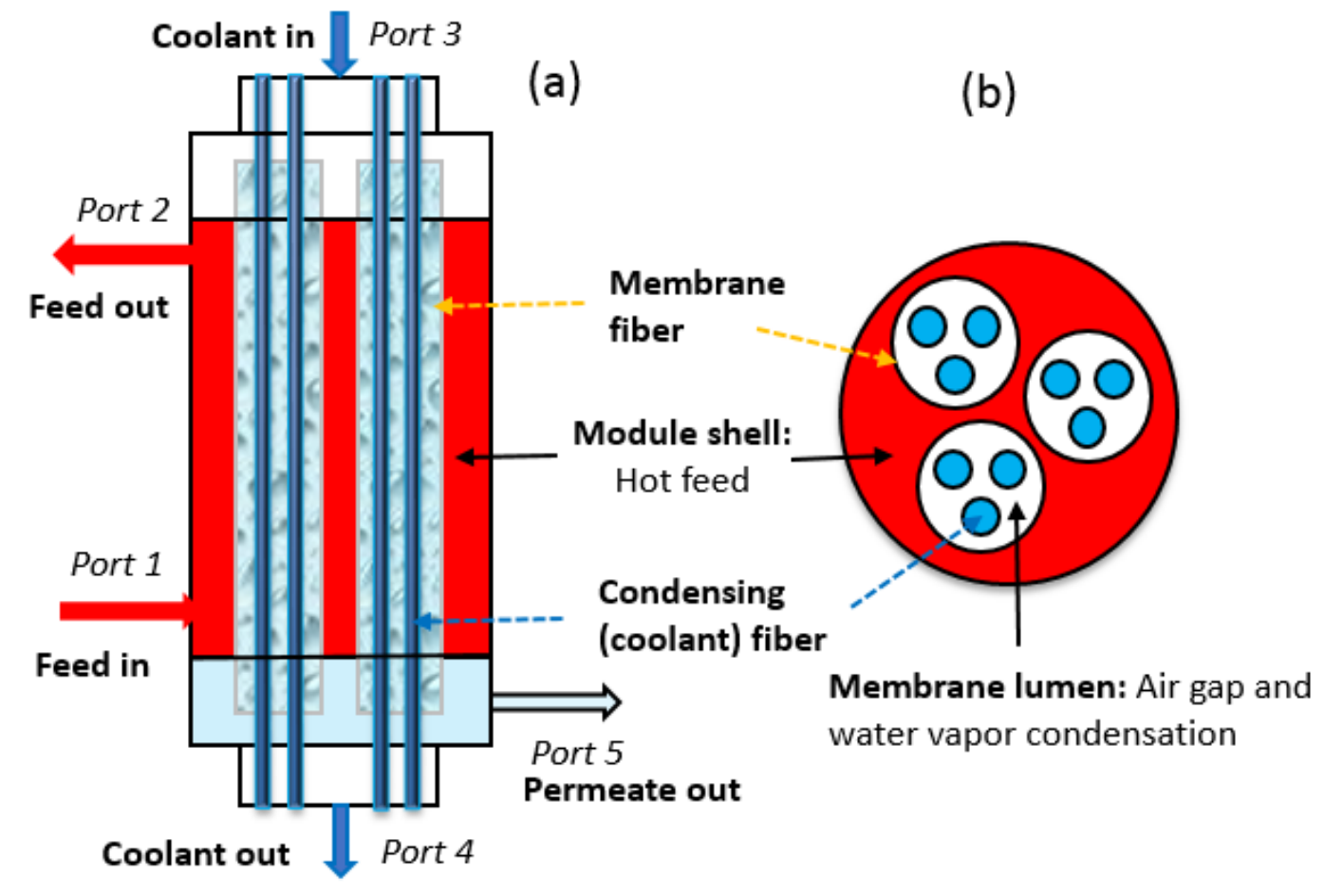

Figure 1. Schematic of the AGMD module (a) and cross-section of the module shell (b).

\subsection{AGMD process}

Figure 2 shows the schematic of the AGMD process. The feed and coolant waters were delivered to the AGMD module from corresponding feed and coolant tanks. The constant temperatures in feed and coolant tanks were maintained by electrical heater (Model C25P, ThermoScientific, Waltham, MA, USA) and chiller (LM series, VWR, Radnor, PA, USA), respectively. Two digital gear pumps (Model GJ-N25.PF1S.A, Cole Parmer, Vernon Hills, IL, USA) were employed to maintain constant feed and coolant flow rates. In the case of AGMD with tubular arrangement, a magnet pump (Iwaki, Tokyo, Japan) was employed for the feed circulation. Mass of produced permeate was monitored with digital balance (Model ML 3002, Metter Toledo, Columbus, OH, USA) and the results were logged into computer through the Labview data acquisition system (National Instruments, Austin, TX, USA).

\subsection{Simulation of the condensation behavior of the water vapor on a condenser fiber outer surface}

In order to investigate the water vapor condensation on the condenser fiber outer surface, a condenser fiber string with a length corresponding to a regular module was potted into plastic tube 
with epoxy resin (Devcon, Shannon, Ireland). The string was fixed in a vertical position and

209 coolant water at $18^{\circ} \mathrm{C}$ was circulated from the top to the bottom by using a digital pump (Model

210 GJ-N25.PF1S.A, Cole Parmer, Vernon Hills, IL, USA). A 250 mL of Milli-Q water was placed in

211 the round bottom flask and the latter was immersed into water bath (Buchi Rotovapor, Flawil,

212 Switzeland) and heated to $85^{\circ} \mathrm{C}$. A $5 \mathrm{~cm}$ glass connector was attached to the flask mouth and its

213 other end faced the middle of the string. The water vapor flew through the glass connector and

214 condensed on the condenser fiber's wall. The formation of water droplets was recorded with a

215 digital camera and the images were processed by using public software Image J (National Institute

216 of Health, USA).

217

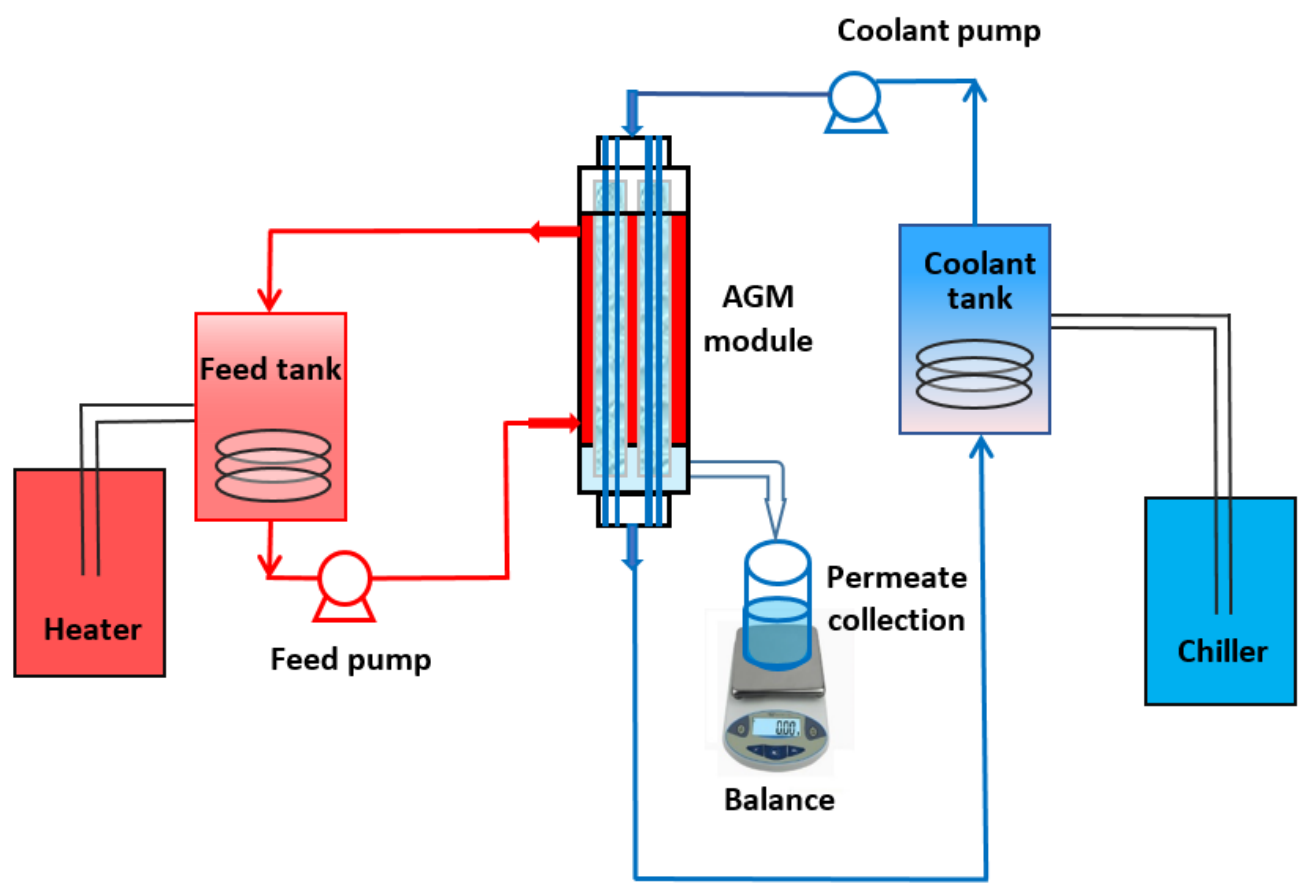

218

219

220

221

222

223

Figure 2. Schematic of the AGMD process.

\subsection{Calculations}

The active diameter of membrane fiber used in estimation of surface area available for vapor permeation was determined as follows:

$$
d_{l m}=\frac{d_{o d}-d_{i d}}{\ln \left(d_{o d} / d_{i d}\right)}
$$


224 where $d_{l m}$ is the average fiber diameter $(\mathrm{mm}), d_{o d}$ is the outside fiber diameter $(\mathrm{mm})$, and $d_{i d}$ is the 225 inner fiber diameter ( $\mathrm{mm})$.

226 The ratios of fiber total surface area/surface area of condenser fibers (R1) and ratio of shell 227 inner surface area/surface area of membrane fibers (R2) were calculated as follows:

$$
R 1(2)=\frac{n(f) S A_{1}}{S A_{2}} 100 \%
$$

228

229

230

$238 J=\frac{m_{W}}{A t}$

$239 \quad R=\left(1-\frac{C_{p}}{C_{f}}\right) 100 \%$

$$
P D=\frac{n(f) S_{1}}{S_{2}} 100 \%
$$
equations, respectively: is the surface area of condenser fiber (membrane fiber) packed into fiber (shell), and $\mathrm{SA}_{2}$ is the surface area of membrane fiber (shell).

The packing density was calculated with respect to density of condenser fibers packed into the membrane fiber (PD1) and density of membrane fibers packed into the shell (PD2) as follows:

where $\mathrm{n}(\mathrm{f})$ is the number of condenser fibers (or membrane fibers) packed into membrane fiber (shell), $\mathrm{S}_{1}$ is the cross-sectional area of condenser fiber (membrane fiber) packed into membrane fiber (shell), and $\mathrm{S}_{2}$ is the cross-sectional area of membrane fiber (shell).

The water vapor flux $(J)$ and rejection of ions $(R)$ were calculated according to the following

240 where $m_{W}$ is the permeate weight $(\mathrm{kg}), A$ is the fiber surface area $\left(m^{2}\right), t$ is the accumulation time

241 (h), $C_{p}$ is the concentration of compound in permeate $(\mathrm{mg} / \mathrm{L})$, and $C_{f}$ is the concentration of 242 compound in feed $(\mathrm{mg} / \mathrm{L})$.

\section{2.7. Analytical methods}

245 Conductivity was measured by a Cond 3210 conductivity meter (WTW GmbH, Weilheim, 246 Germany). The $\mathrm{B}^{3+}, \mathrm{Na}^{+}, \mathrm{Ca}^{2+}$ and $\mathrm{Mg}^{2+}$ concentrations were measured by an ICP-MS system with 247 an ASX-500 autosampler (7500 Series, Agilent Technologies, Santa Clara, CA, USA). 248 Concentrations of dissolved organic carbon (DOC) were measured by the Shimadzu Total Organic 249 Carbon Analyzer (TOC-V CSH Model, Shimadzu Corporation, Japan). The surface morphology 
of fibers was analyzed with the field emission scanning electron microscopy (FE-SEM, Quanta 200 FEG System, FEI, OR, USA).

The results reported in this study represent typical AGMD runs. Some random experiments corresponding to each tested membrane type (Modules 3, 7, 8 and 10) were duplicated to check the reproducibility of the results. The values of standard deviations in duplicate runs were in the range of $0.07-0.37$.

\section{Results and Discussion}

\subsection{Effect of module configuration on water vapor flux}

Figure 3 shows the effect of module configuration (condenser fibers packed inside membrane fiber (capillary 1, module 3, see Table 3) versus condensers packed outside membrane fiber (capillary 1, module 7, see Table 3) on corresponding water vapor flux at different feed flow rates and at a feed temperature of $70^{\circ} \mathrm{C}$. For comparison purpose, the number of membrane fibers and condenser fibers was kept the same for both modules $(n=6, f=2)$. As seen in Figure 3, higher vapor fluxes were achieved when condenser fibers were packed inside the membrane fiber (module 3) comparing to the outside packing arrangement (module 7) at any tested feed flow rate. At a maximum feed flow rate of $600 \mathrm{~mL} / \mathrm{min}$, a $10 \%$ increase in vapor flux was observed in module 3 compared to that of module 7 . When condenser fibers were packed inside the membrane fiber, their distribution inside the lumen was even, providing equal circulation of flow along the masstransfer area. As a result, the vapor flux would be maximized. On contrary, it was technically hard to achieve even distribution of condenser fibers and membrane fibers for the case of outside packing module. The mass-transfer process in this case would be distorted, leading to a reduction in the vapor flux. Therefore, the process performance of module 7 was less effective. A similar constrains during fabrication of hollow fiber MD modules were reported previously. Therefore, El-Bourawi et al [41] quoted a 58\% flux decline due to random distribution of fibers in the module shell. Singh and Sikar [28] observed similar deficiency in the hollow fiber AGMD module when membrane fibers and condenser fibers were placed inside the shell. The authors attributed the decrease in vapor flux to the inefficient mixing of hollow fibers and condenser fibers inside the shell. In our study the condenser fibers were placed inside the membrane fibers. The suggested arrangement not only facilitated better vapor fluxes, but also, if expanded to a larger scale, is expected to provide a reduction in module footprint and a better internal heat recovery compared 
281 to outside condenser fibers packing by potential saving of space inside the shell enabling to install 282 more membrane fibers which otherwise would be occupied by condenser fibers of typical 283 arrangement.

284

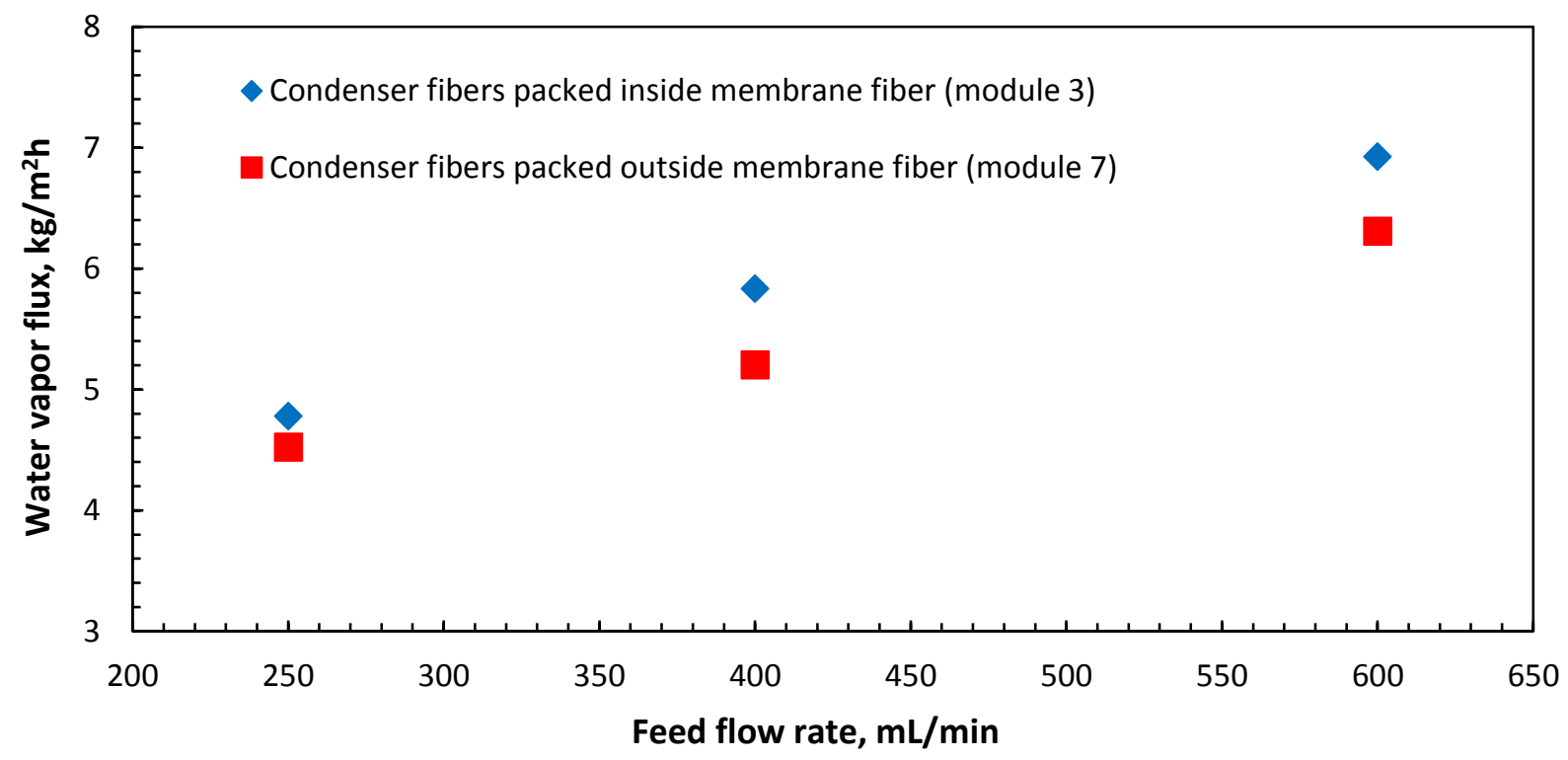

285

Figure 3. Effect of module configuration (inside $v s$ outside fiber condensers packing) on water vapor flux. Modules: 3 and 7; capillary 1; number of membrane fibers (f): 2; number of condenser fibers per membrane fiber $(\mathrm{n}): 3$. Feed temperature: $70^{\circ} \mathrm{C}$; coolant temperature: $18^{\circ} \mathrm{C}$; coolant flow rate: $250 \mathrm{~mL} / \mathrm{min}$.

\subsection{Effect of feed temperature and number of condenser fibers on water vapor flux}

Figure 4 presents the effect of temperature on vapor flux as a function of number of condenser fibers packed into a single capillary ( $\mathrm{f}=2, \mathrm{n}=1 \div 4$, modules $1 \div 4$ ). As seen in the Figure 4, vapor flux increased with the temperature increase for all tested modules due to increase in vapor pressure of the hot feed. As such, more vapor will be diffused from the outer side of membrane fiber to the lumen side. However, the increment of flux increase at a particular temperature was determined by the number of condenser fibers installed in a single capillary. At lower feed temperatures $\left(50^{\circ} \mathrm{C}\right.$ and $\left.60^{\circ} \mathrm{C}\right)$, the difference in vapor fluxes among modules was small, while more pronounced difference in vapor fluxes was observed with increasing feed temperature from $60^{\circ} \mathrm{C}$ to $85^{\circ} \mathrm{C}$. As vapor fluxes for modules $1 \div 3$ (corresponding to $\mathrm{n}=1 \div 3$ ) followed exponential increase in vapor flux (which is a characteristic feature of the MD process), the vapor flux increase 
observed in module 4 , which contained the maximum number of condenser fibers inside the lumen $(\mathrm{n}=4)$, followed a linear trend with $\mathrm{R}^{2}=0.9887$. The highest vapor flux achieved in this module $\left(13.5 \mathrm{~kg} / \mathrm{m}^{2} \mathrm{~h}\right)$ at a feed temperature of $85^{\circ} \mathrm{C}$ was significantly lower than the vapor fluxes observed under the same operating conditions in modules 2 and 3 with less number of condenser fibers (14.8 $\mathrm{kg} / \mathrm{m}^{2} \mathrm{~h}$ and $18.0 \mathrm{~kg} / \mathrm{m}^{2} \mathrm{~h}$, respectively). This corresponded to $8 \%$ and $25 \%$ of vapor flux decline relative to modules 2 and 3 , respectively. To explain such observed trend we conducted an experiment to simulate the condensation behavior of the water vapor on a condenser fiber surfaces. As it is shown in Figure 5, the water vapor forms droplets on the condenser fiber surface which grows to large diameter before it falls down by gravity. This was not expected since the condenser fibers were made of PP (hydrophobic surface). Nonetheless, the condensate droplets grew to about the same diameter of the condenser fiber all around causing bridging between condenser fibers. Such bridging phenomenon reduces the heat transfer across the condenser fibers by two mechanisms. First, it reduces the available surface area for condensation. Second, it increases condenser fibers wall thickness and limit their heat transfer by conduction. The optimal number of condenser fibers observed can be explained as follows: the mass transfer resistance in the AGMD process depends on the air gap achieved in the module. The air gap in turn will decrease with increasing packing density of condenser fibers, i.e., the higher the number of condenser fibers and its corresponding condensation surface area, the higher the vapor flux would be achieved. The increase in the vapor flux with increasing condensation area and reducing air gap was demonstrated by several authors [32]. On the other hand, as postulated by Cheng et al. [27], the air gap thickness cannot be reduced indefinitely without taking into account the gap bridging effect. In other words, the free space inside the membrane fiber lumen which is available for condensed vapor will decrease with an increase in the total surface area of condenser fibers. As such, there would exist an optimal number of condenser fibers which would facilitate high condensation area while maintaining small mass transfer resistance. 


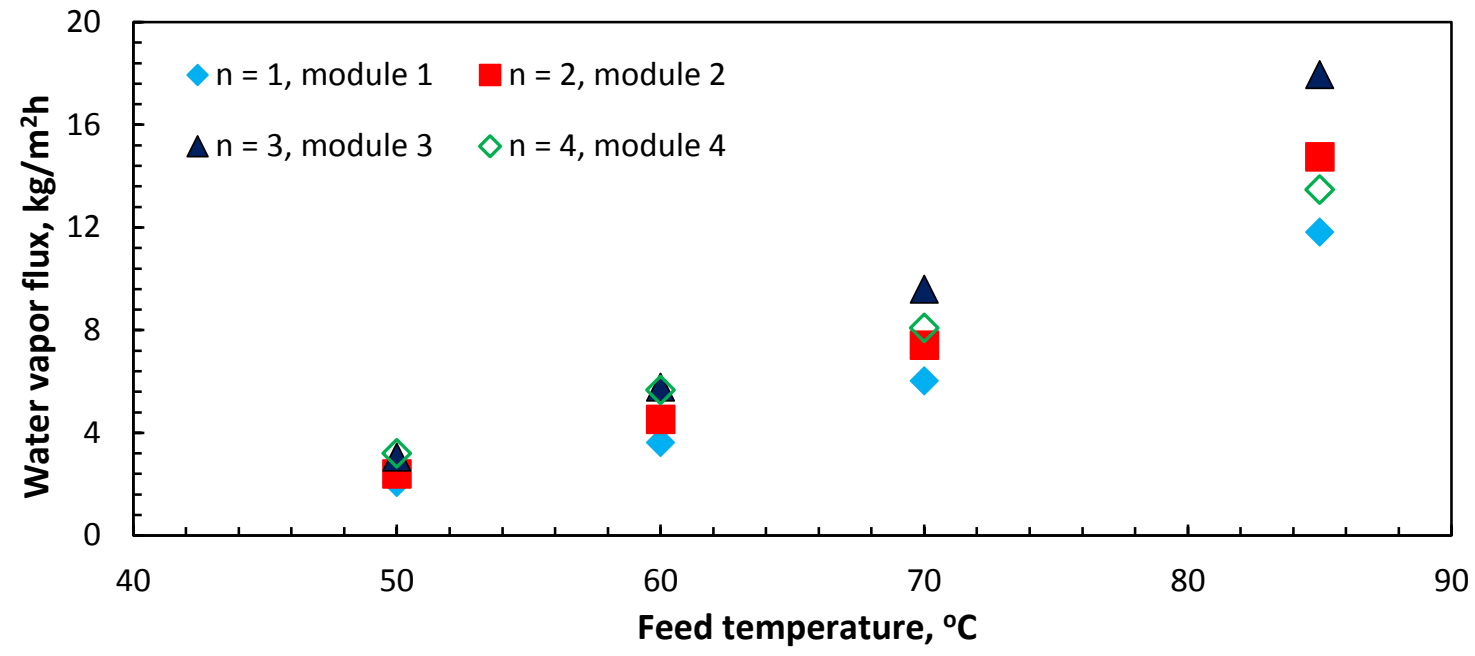

329

330

331

332

333

Figure 4. Effect of number of condenser fibers (n) inside membrane fiber on water vapor flux at different feed temperatures. Modules: $1 \div 4$; capillary 1; number of membrane fibers (f): 2 ; coolant temperature: $18^{\circ} \mathrm{C}$; feed flow rate: $1,100 \mathrm{~mL} / \mathrm{min}$; coolant flow rate: $280 \mathrm{~mL} / \mathrm{min}$.

A formation of condensed water droplets with sizes comparable with condenser fiber diameter was observed

Figure 5. A digital image of the condenser fiber with water droplets formed on its outer surface

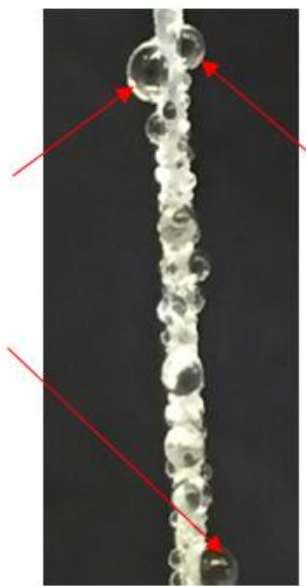

Cross-section of membrane fiber lumen with four condenser fibers inside

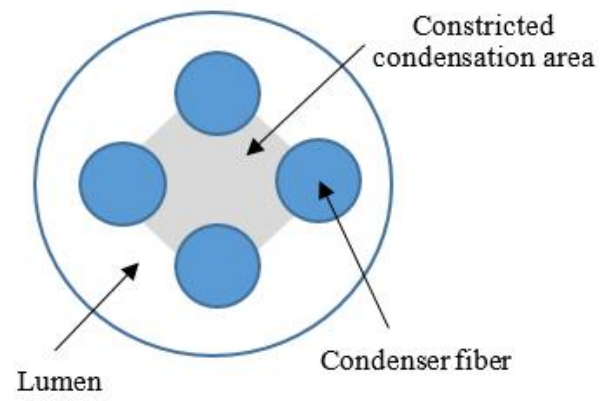
(right). 


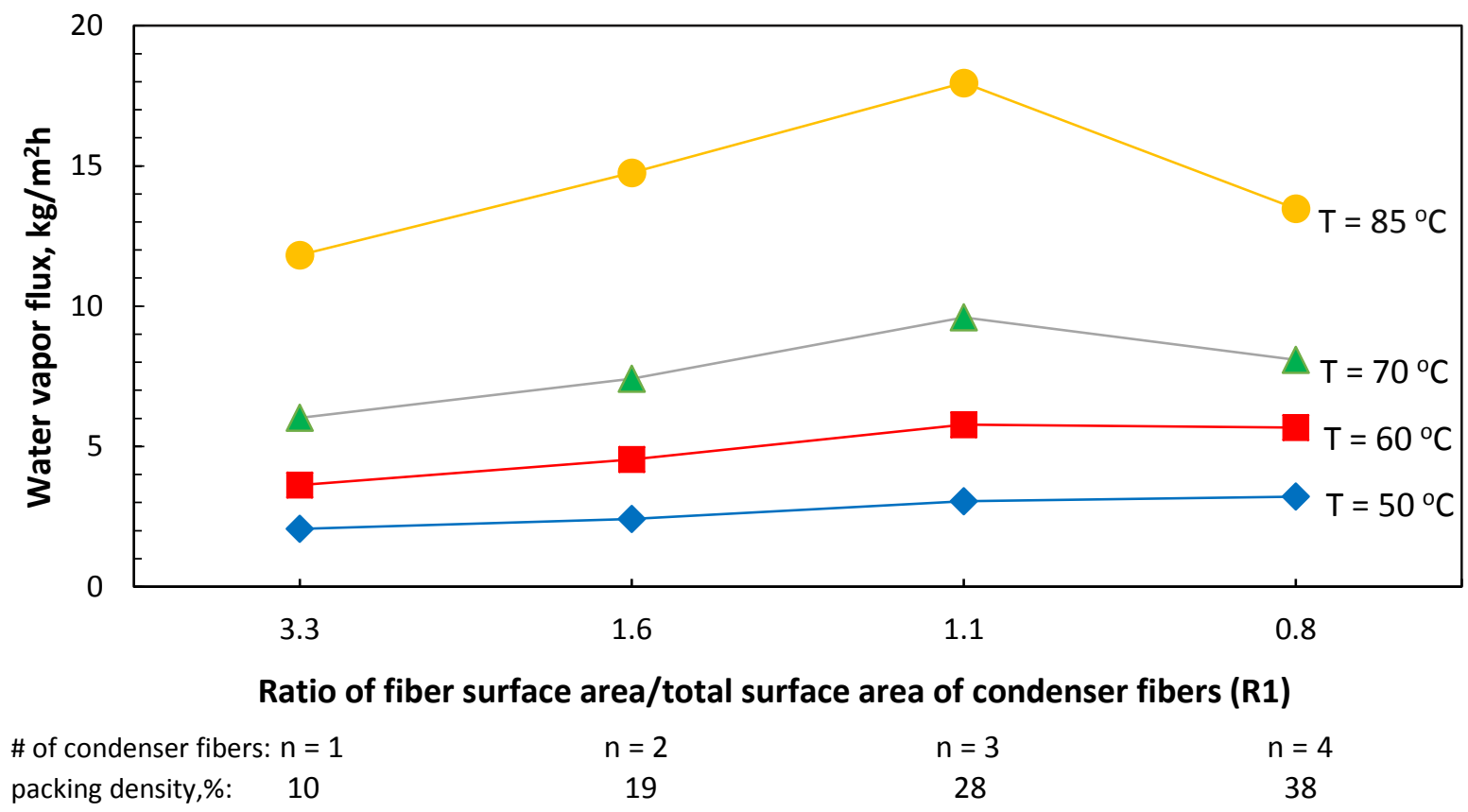

Figure 6. Effect of ratio of membrane fiber surface area/total surface area of condenser fibers (R1) on water vapor flux at different feed temperatures. Modules: $1 \div 4$; capillary 1; number of membrane fibers (f): 2 ; coolant temperature: $18^{\circ} \mathrm{C}$; feed flow rate: $1,100 \mathrm{~mL} / \mathrm{min}$; coolant flow rate: $280 \mathrm{~mL} / \mathrm{min}$.

The lower condensate removal rate compared to permeate production rate would cause permeate flooding inside the AGMD module as it has been recently addressed in a number of studies [42-45]. Despite the improved permeate flux, the thermal efficiency of the process is decreased due to the air replacing water which has poorer insulating properties [42]. By increasing the surface area of condenser fibers inside the lumen, the flooding is likely to become a limiting factor. Recently, Hitsov et al. [43] calculated the flooded fraction (X) inside the air gap with respect to different $\Delta \mathrm{Ts}$ (difference between the feed and coolant temperatures) and observed an increase in $\mathrm{X}$ as $\Delta \mathrm{T}$ increased (i.e., the values of flooded fraction were higher at higher vapor fluxes). Similarly, Warsinger et al. [42] investigation on condensation flow regimes in AGMD suggested that flooding and trapping of droplets would be minimized in case of lower AGMD fluxes. These results are well correlated with our observations when a significant increase in vapor flux achieved at high feed temperatures at $\mathrm{n}=3$ was decreaded when the number of condenser fibers $\mathrm{n}$ was further increased to 4 . To better illustrate our findings, we calculated the ratios of the total active 
surface area of membrane fiber to the total outer surface areas of condenser fibers (R1) for modules 1-4 (see Table 3), and plotted those values against corresponding vapor fluxes at each tested feed temperature (Figure 6). As shown in Figure 6, different trends were observed for vapor fluxes with respect to different feed temperatures. At a lowest feed temperature of $50^{\circ} \mathrm{C}$, the vapor fluxes increased with decreasing this ratio regardless of the number of condenser fibers. When the feed temperature was further raised to $60^{\circ} \mathrm{C}$, the vapor fluxes increased with decreasing R1 from 3.3 to 1.1 (corresponding to an increase from 1 to 3 ) and no significant difference was observed for vapor fluxes corresponding to $\mathrm{R} 1=1.1$ and 0.8 ( $\mathrm{n}=3$ and $\mathrm{n}=4$, respectively). At a feed temperatures of $70^{\circ} \mathrm{C}$ and $85^{\circ} \mathrm{C}$ the vapor fluxes as a function of $\mathrm{R} 1$ passed the inflection point. The fluxes increased with $\mathrm{R}$ decrease from 3.3 to 1.1 and then went down when $\mathrm{R} 1$ was further decreased to 0.8 ( $\mathrm{n}=$ 4). At low feed temperatures, the vapor fluxes were low, therefore, there would be enough free space inside the lumen for vapor condensation regardless of number of condenser fibers so the vapor fluxes increased. As opposite, at high feed temperatures, the deficiency of the free space inside the lumen would start to appear with the addition of the fourth condenser so vapor fluxes will decrease. The optimal R1 and packing density (PD) which would provide the highest vapor flux were found to be 1.1 and $28 \%$, respectively.

\subsection{Effect of feed and coolant flow rates on vapor flux at different number of condenser fibers}

Figure 7 shows the effect of the feed (6a) and coolant (6b) flow rates on water vapor flux at different number of condenser fibers. In this study, the number of membrane fibers was fixed at $\mathrm{f}$ $=2$, the feed flow rate was varied from $280 \mathrm{~mL} / \mathrm{min}$ to $1,100 \mathrm{~mL} / \mathrm{min}$, and the coolant flow rate was varied from $300 \mathrm{~mL} / \mathrm{min}$ to $1,000 \mathrm{~mL} / \mathrm{min}$. 

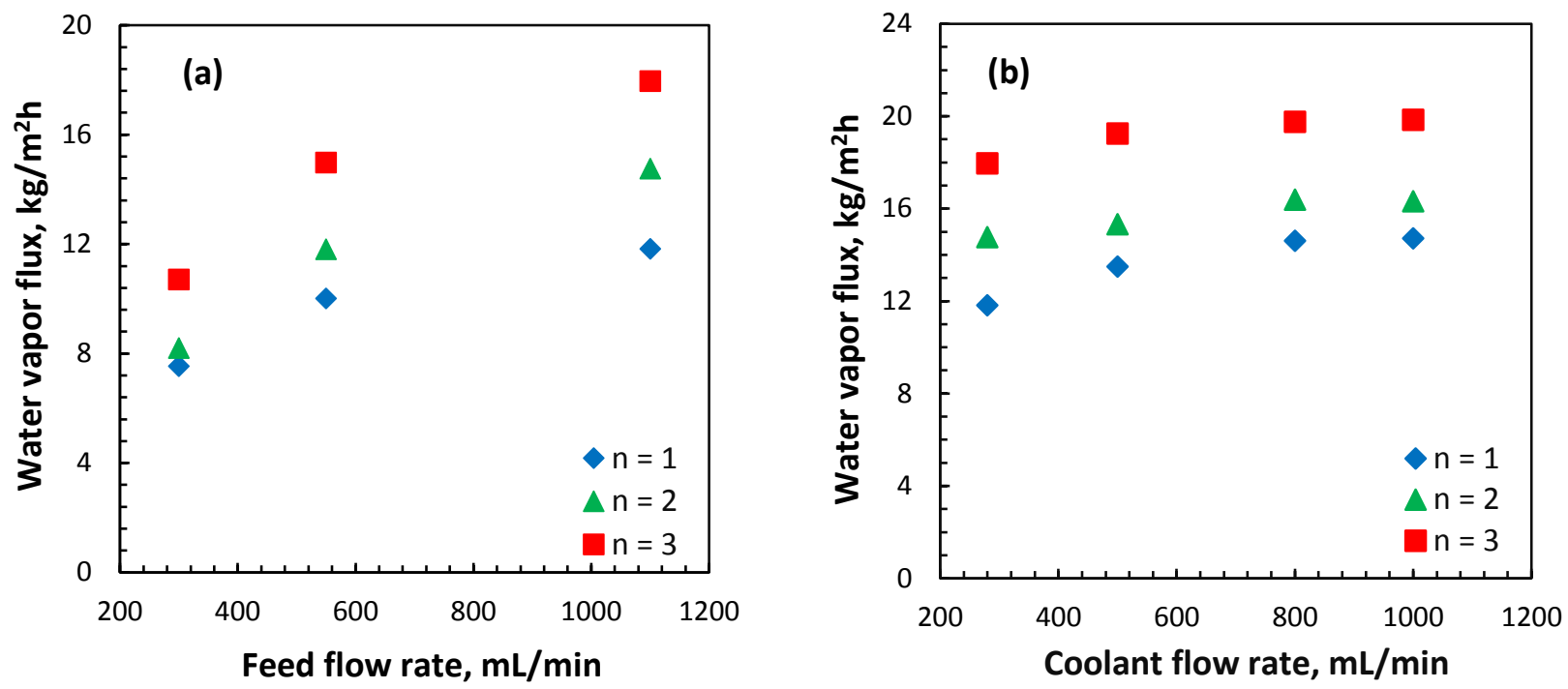

381

Figure 7. Effect of number of fiber condensers inside the membrane fiber (n) on water vapor

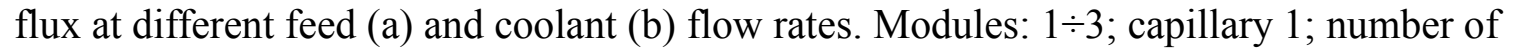
membrane fibers (f): 2 ; feed temperature: $85^{\circ} \mathrm{C}$; coolant temperature: $18^{\circ} \mathrm{C}$; (a) coolant flow rate was fixed at $280 \mathrm{~mL} / \mathrm{min}$; (b) feed flow rate was fixed at 1,100 $\mathrm{mL} / \mathrm{min}$.

Effect of feed flow rate. As shown in Figure 7a, vapor flux has significantly increased with increasing feed flow rate and with increasing the number of condenser fibers from 1 to 3 . Therefore, at optimal number of condenser fibers $(n=3)$, the vapor flux increased by $40 \%$ when the feed flow rate was increased from $300 \mathrm{~mL} / \mathrm{min}$ to $1,100 \mathrm{~mL} / \mathrm{min}$. The increase in the feed flow rate enhanced the flow near the membrane surface. As such, temperature polarization at the hot feed side was reduced, causing an enhancement of thermal efficiency of the process. Cheng et al. [26] and Soukane et al. [46] showed that heat transfer coefficient increased with increasing feed flow rate in DCMD process; a similar trend was reported for the AGMD process [27]. Other factors causing an increase in vapor flux at higher feed flow rates are corresponding decreases in concentration polarization and retention time of the feed in membrane module, which would result in higher temperature difference between the two sides of membrane [47].

When comparing the extent of vapor flux increase with respect to number of condenser fibers, a lower flux increase (36\%) was observed at $n=1$ as compared to that of $40 \%$ at $n=3$. The heat exchanged between the cold and hot sides of the membrane fiber is determined by the surface area of condensation, which varied depending on the number of condenser fibers used. At $n=1$, the 
area would be the smallest, therefore the amount of heat transferred from the feed side to the coolant side per unit of condensing area was expected to be higher as compared to those at larger n. In other words, the driving force of the AGMD process decreases at smaller surface area of condenser fibers, resulting in smaller increment of vapor flux increase.

Effect of coolant flow rate. As shown in Figure 7b, although the increase in the coolant flow rate increased the vapor flux, this increase was less pronounced compared to the feed flux flow rate increase. The increment of coolant flow rate increase varied with the number of condenser fibers in the AGMD module. This effect can be explained by the fact that the flow rate of coolant which was supplied to the module inlet was the same for all tested number of condenser fibers. However, after entering Port 3 (Figure 1), depending on the module type, the coolant flow was split into a number of condenser fibers. As known, the hydraulic resistance in a pipe and corresponding pressure drop increased with increasing the number of channels (or, in our case, condensers) [48]. As such, the actual flow rate of the coolant in condensers would increase with decreasing their number from 4 to 1 . Such a decrease in flow rate will cause the increase in coolant residence time in the AGMD module. As a result, the temperature polarization will be induced. As seen in Figure $7 \mathrm{~b}$, when the coolant flow rate increased from 280 to $1,000 \mathrm{~mL} / \mathrm{min}$, the extent of vapor flux increase was $19 \%$ at $\mathrm{n}=1$ compared to only $9 \%$ at $\mathrm{n}=3$. Nevertheless, when comparing actual vapor fluxes, higher values were observed for $n=3$ regardless of the coolant flow rate due to significantly higher condensation area.

\subsection{Effect of temperature on water vapor flux at different number of membrane fibers}

The effect of the number of membrane fibers on vapor flux was also assessed in our study. To test this effect, modules with different numbers of membrane fibers ( $f=1 \div 3$ ) and three condenser fibers inside each membrane fiber $(\mathrm{n}=3)$ were fabricated (modules 3, 5 and 6, presented in Table 3). As shown in Figure 8, the vapor flux increases with increasing feed temperature from $50^{\circ} \mathrm{C}$ to $85^{\circ} \mathrm{C}$ for all three tested modules. While at low feed temperatures $\left(50^{\circ} \mathrm{C}\right.$ and $\left.60^{\circ} \mathrm{C}\right)$ there was no significant difference in the vapor fluxes between the tested modules, the difference in vapor fluxes started to appear when the feed temperature was further increased. At highest feed temperature of $85^{\circ} \mathrm{C}$, the water vapor flux achieved with module 3 with two membrane fibers was higher (18 $\left.\mathrm{kg} / \mathrm{m}^{2} \mathrm{~h}\right)$ compared to modules with one membrane fiber $\left(17 \mathrm{~kg} / \mathrm{m}^{2} \mathrm{~h}\right)$ or three membrane fibers $(15$ 
$\left.432 \mathrm{~kg} / \mathrm{m}^{2} \mathrm{~h}\right)$. A combined effect of feed flow rate and membrane fibers packing density can be 433 accounted for the observed vapor flux patterns. A higher inlet feed flow at lower number of 434 membrane fibers will enhance the convection heat transfer and reduce the feed residence time. As 435 such, the vapor flux will increase. However, as the number of membrane fibers increased, more 436 437 vapor will be transferred across the membrane reducing the temperature difference between the

438 439 440 441 feed and coolant sides. Therefore, the driving force of the process will also be reduced. Hence, the optimization of the vapor flux with respect to number of membrane fibers is a trade-off between increasing the total surface area of membrane fiber and reducing the process efficiency at high packing densities.

To better visualize the observed trend, we plotted the vapor fluxes as a function of membrane fibers packing density at different feed temperatures (Figure 9). A clear effect of membrane fiber bundling on process performance was observed. An increase in packing density of membrane fibers inside the shell from $16 \%$ to $48 \%$ had negligible effect on vapor flux production at $50^{\circ} \mathrm{C}$ and $60^{\circ} \mathrm{C}$. On the contrary, maximized vapor fluxes were achieved at a packing density of $32 \%$ (corresponding to $\mathrm{f}=2$ ) at $70^{\circ} \mathrm{C}$ and $85^{\circ} \mathrm{C}$. A similar effect of reducing the efficiency of AGMD process after a number of fibers reached a threshold (determined by module configuration and type of fiber) was observed by other researchers [28, 32].

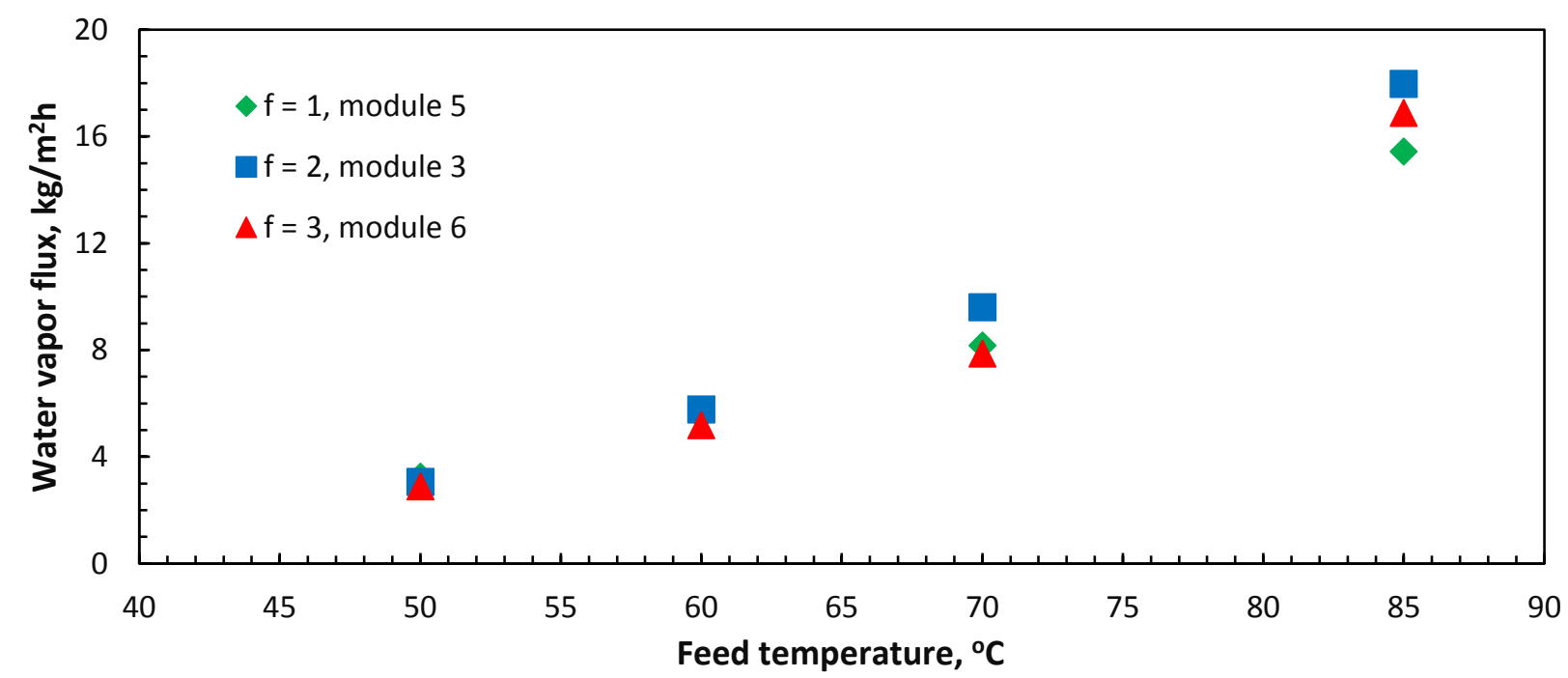

Figure 8. Effect of number of membrane fibers (f) on water vapor flux as a function of feed temperature. Modules: 3, 5 and 6; capillary 1; number of condenser fibers (n) per lumen: 3; coolant temperature: $18^{\circ} \mathrm{C}$; feed flow rate: $1,100 \mathrm{~mL} / \mathrm{min}$; coolant flow rate: $280 \mathrm{~mL} / \mathrm{min}$. 


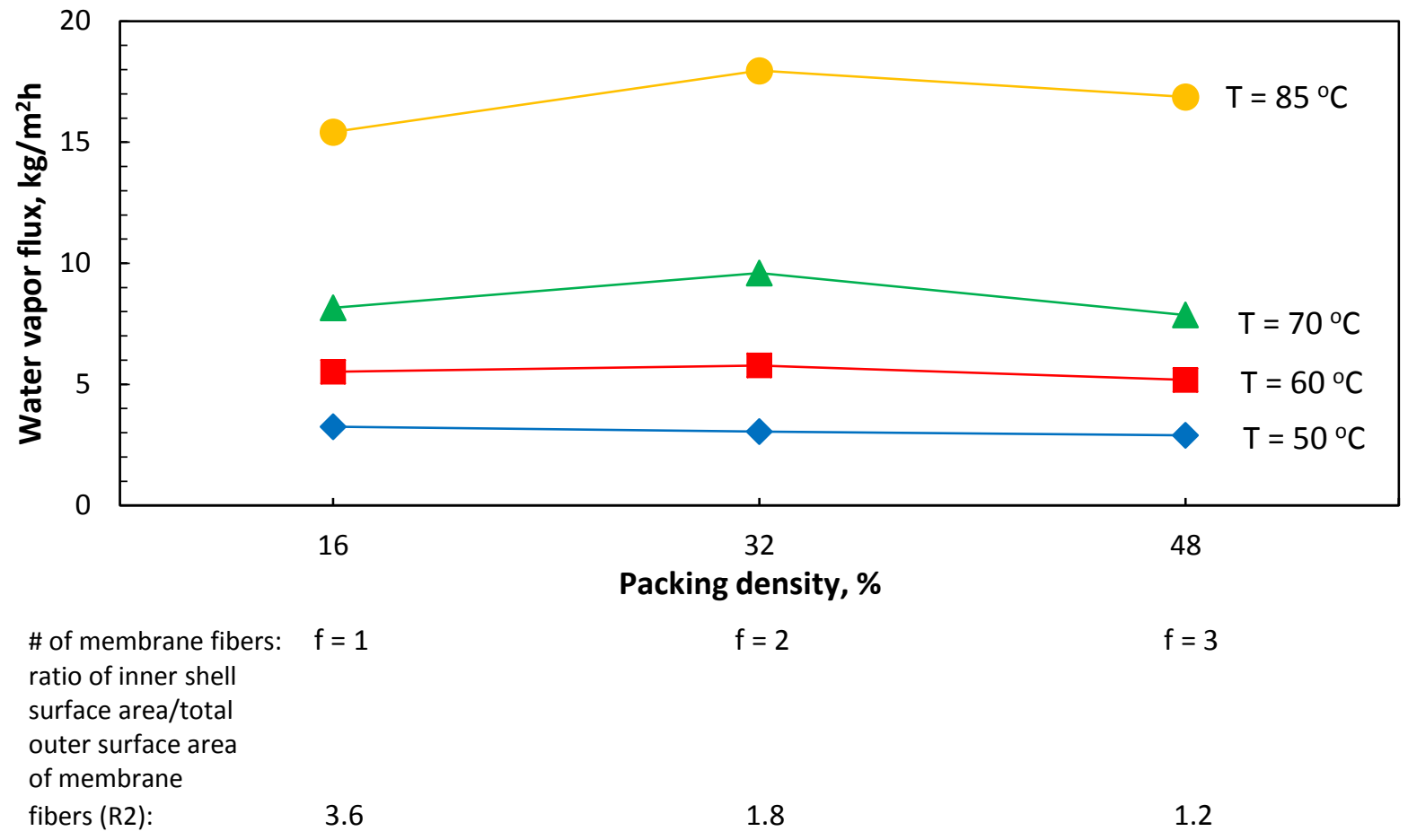

Figure 9. Effect of ratio of inner surface area of shell/total surface area of membrane fibers on water vapor flux at different feed temperatures. Modules: 3, 5 and 6; capillary 1; number of condenser fibers $(\mathrm{n}): 3$; coolant temperature: $18^{\circ} \mathrm{C}$; feed flow rate: $1,100 \mathrm{~mL} / \mathrm{min}$; coolant flow

\subsection{Effect of feed flow rate on vapor flux at different number of membrane fibers}

461 Figure 10 shows the effect of the feed flow rate on vapor flux at different number of membrane 462 fibers $(\mathrm{f}=1 \div 3)$ at a feed temperature of $85^{\circ} \mathrm{C}$ and optimal number of condenser fibers inside membrane fiber $n=3$. As shown in Figure 10, the vapor flux increased with increasing feed flow rate from 300 to $1,100 \mathrm{~mL} / \mathrm{min}$ for all tested $\mathrm{f}$. When comparing the vapor fluxes at different $\mathrm{f}$, the 465 lower vapor fluxes were measured at $\mathrm{f}=1$ at any tested feed flow rate. When the number of 466 membrane fibers was increased, the vapor fluxes also increased, but the increment of such an 467 increase was different for modules with two or three membrane fibers. At feed flow rates of 300 $468 \mathrm{~mL} / \mathrm{min}$ and $550 \mathrm{~mL} / \mathrm{min}$, the vapor fluxes of both modules were similar while when the flow rate 469 was further increased to $1,100 \mathrm{~mL} / \mathrm{min}$, the vapor flux of module 3 with $\mathrm{f}=2$ was higher as 470 compared to that of module 6 with $\mathrm{f}=3$. The increase in the feed flow reduces the temperature 471 polarization at the bulk feed and cause a decrease in the residence time of the feed and convective 
472 heat transfer in the module channel. On the contrary, as discussed above, the increase in vapor flux 473 will lower the temperature difference across the membrane. This effect will be more noticeable at 474 higher feed fluxes, therefore, at feed flow rate of 1,100 mL/min, the AGMD module with a number 475 of membrane fibers $\mathrm{f}=2$ performed better than that of $\mathrm{f}=3$.

476

477

478

479

480

481

482

483

484

485

486

487

488

489

490

491

492

493

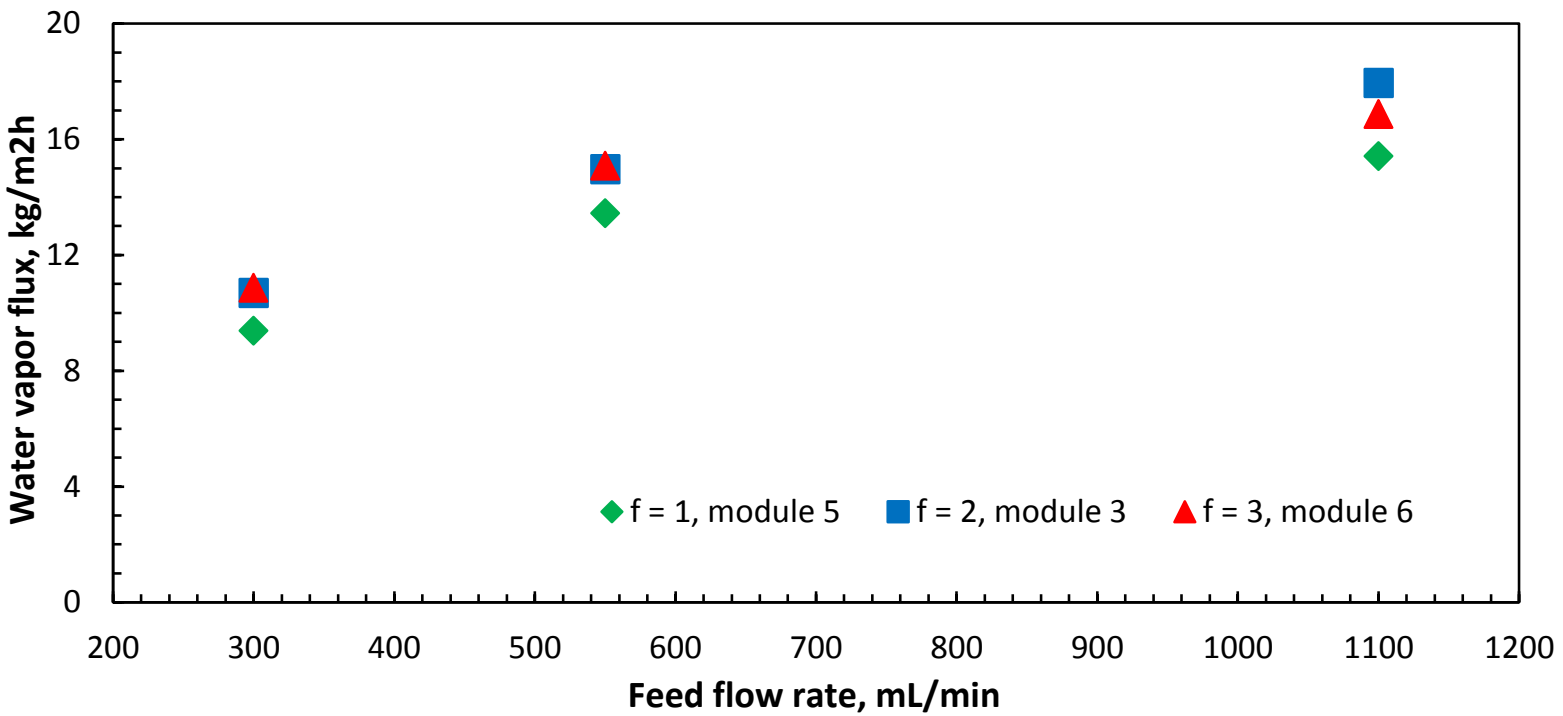

Figure 10. Effect of number of membrane fibers inside the shell on vapor flux at different feed

flow rates. Modules: 3, 5 and 6; capillary 1; number of condenser fibers (n) $=3$; feed temperature: $85^{\circ} \mathrm{C}$; coolant temperature: $18^{\circ} \mathrm{C}$; coolant flow rate: $280 \mathrm{~mL} / \mathrm{min}$.

\subsection{Effect of membrane thickness on AGMD performance}

To investigate the effect of membrane characteristics on process performance, three types of PP membranes with different IDs and wall thicknesses were tested (Table 2). In addition to already discussed modules $1 \div 8$ fabricated with capillary 1 , module 8 was fabricated with five capillaries (maximum possible number of membrane fibers per shell), and with one condenser per membrane fiber ( $\mathrm{n}=1$, maximum possible number of condenser fibers per membrane fiber). Modules 9 and 10 contained three tubes (maximum possible number of tubes per shell) and different number of condenser fibers ( $\mathrm{n}=8$ and 20 for modules 9 and 10, respectively).

The SEM microscopy of membranes (Figure 11) revealed that regardless of the wall thickness, the membranes had similar uniform dense structure. Given similar morphology and pore size $(0.2$ $\mu \mathrm{m})$ of these membranes, it was of particular interest to compare their efficiency in the AGMD process as it allows to optimize the process performance not only with respect to operating 
conditions but also to a membrane type. Figure 12 displays the effect of the number of condenser fibers on water vapor flux for modules 9 and 10. The capillary 2 had a wall width of $800 \mu \mathrm{m}$ which is the highest wall thickness among the three tested membranes. The numbers of condenser fibers in these tests were selected arbitrary to investigate the effect of low condensation area versus high condensation area on process performance in the case of AGMD module built with a membrane having high wall thickness. As shown in Figure 12, the vapor fluxes below $5 \mathrm{~kg} / \mathrm{m}^{2} \mathrm{~h}$ were achieved with module 9 even at a feed flow rate of $4,000 \mathrm{~mL} / \mathrm{min}$. In this case, the ratio of the surface area of tubes to the surface area of condenser fibers (R2) was estimated to be 2.0; i.e., the membrane surface area was twice larger than the total condensation area. To achieve higher condensation area, we increased the number of condenser fibers in module 11 to 20 ( $R 2=0.8)$. However, this led the vapor fluxes to further decline regardless of the feed flow rate. When comparing Figures 6 and 12 , one can see that the increase in the wall thickness negatively affected the vapor flux. Therefore, at the same feed temperature of $85^{\circ} \mathrm{C}$ and $\mathrm{R} 2=0.8$, module 4 which utilized capillary 1 with wall thickness of $400 \mu$ m produced vapor flux almost four times higher compared to module $10\left(13.5 \mathrm{~kg} / \mathrm{m}^{2} \mathrm{~h}\right.$ and $3.6 \mathrm{~kg} / \mathrm{m}^{2} \mathrm{~h}$, respectively).

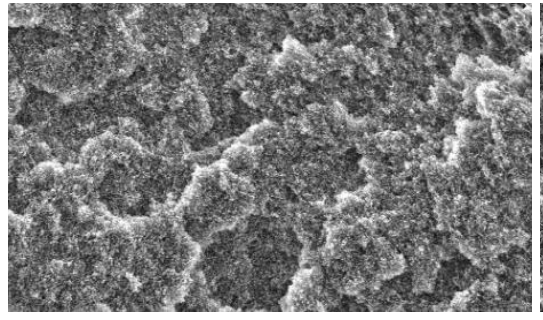

(a)

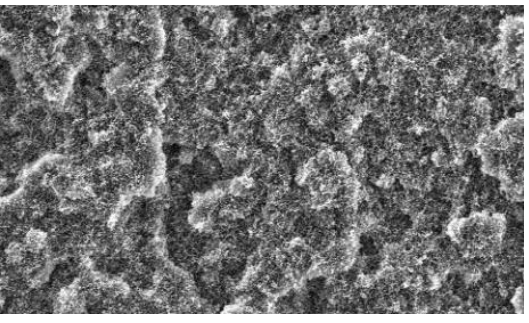

(b)

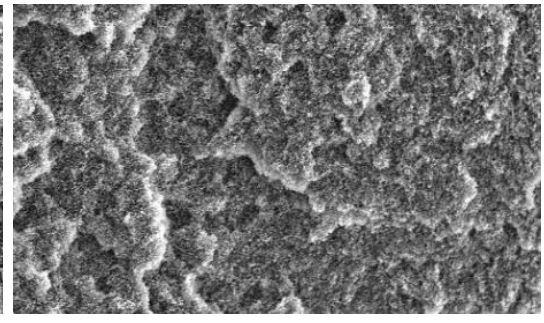

(c)

Figure 11. Cross-sectional SEM images of membrane structures of capillary 1 (a), capillary 2 (b) and tubular (c). which is the smallest among the three tested membranes. Figure 12 shows the vapor fluxes observed at different temperatures. For comparison purposes, Figure 13 also contained the vapor fluxes achieved under similar operating conditions with module 3 ( $f=2, n=3$, represented the module with the highest achieved vapor fluxes among all modules utilizing capillary 1) and module 4 ( $\mathrm{f}=3, \mathrm{n}=3$, had the maximum possible number of capillaries 1 in a shell). As shown in 
521 Figure 13, the water vapor fluxes obtained with module 8 were higher than those obtained with 522 modules 3 and 6 at any tested feed temperature. However, the ratio of the membrane fiber surface 523 area to condenser fibers surface area (R1) of module 8 was twice higher than those of modules 3 524 and 6 (2 and 1.1, respectively). In other words, the observed vapor flux of module 8 was produced 525 when surface area exceeded condenser fibers surface area by almost twice while the vapor fluxes 526 produced in modules 3 and 4 were achieved when the capillary surface area was similar to 527 condensers surface area. Given that the difference in vapor fluxes between modules 8 and 3 was 528 only $5 \%\left(19 \mathrm{~kg} / \mathrm{m}^{2} \mathrm{~h}\right.$ and $\left.18 \mathrm{~kg} / \mathrm{m}^{2} \mathrm{~h}\right)$, module 3 can be viewed as more suitable in terms of both 529 vapor flux values and optimal ratio of membrane fiber surface area to condenser fibers surface 530 area.

531 In all our AGMD experiments using Red Sea water as feed solution, salt rejection was always 532 above $99.9 \%$ corresponding to permeate conductivity values below $20 \mu \mathrm{s} / \mathrm{cm}$.

533

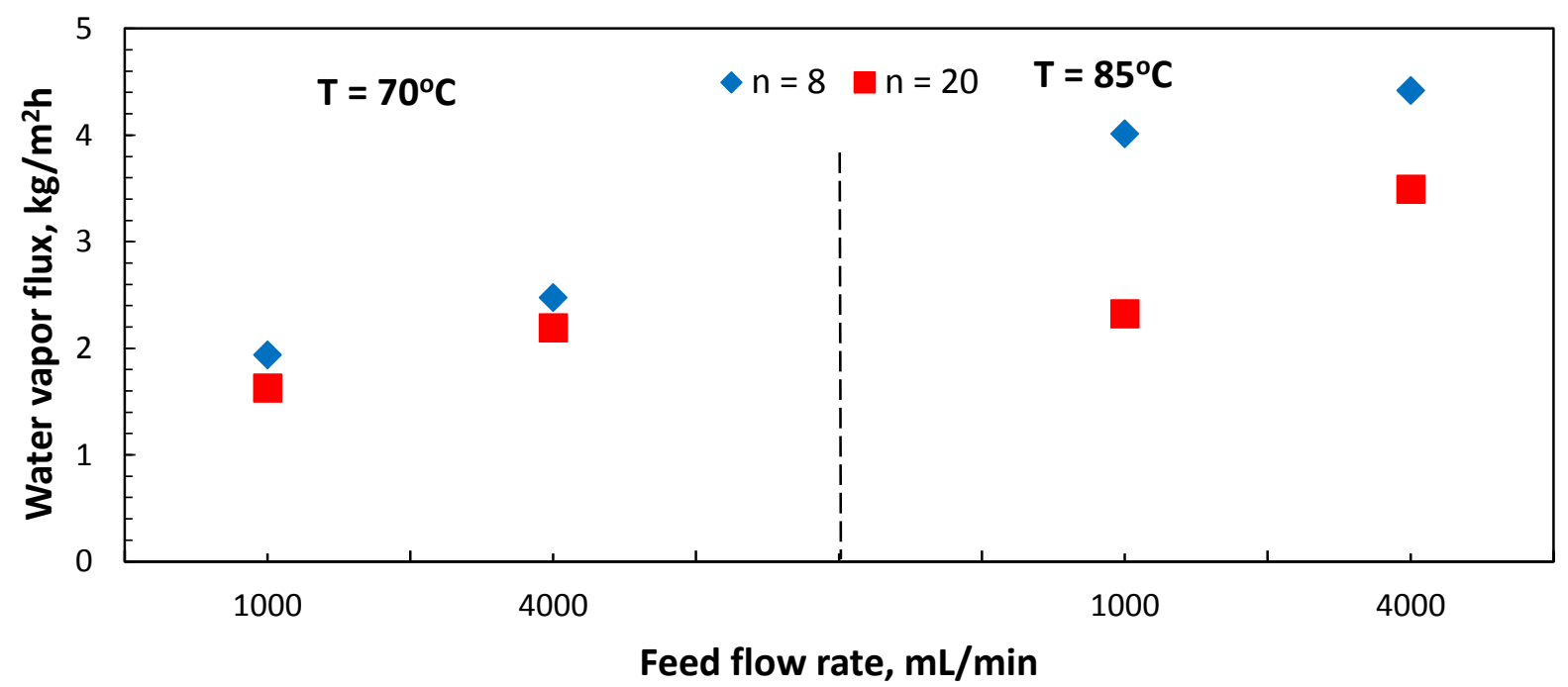

534

535

536

537

538

539

540

541
Figure 12. Effect of number of condenser fibers (n) inside the tubular membrane on vapor flux at different temperatures and feed flow rates. Modules: 9 and 10; coolant temperature: $18^{\circ} \mathrm{C}$; coolant flow rate: $1,300 \mathrm{~mL} / \mathrm{min}$. 


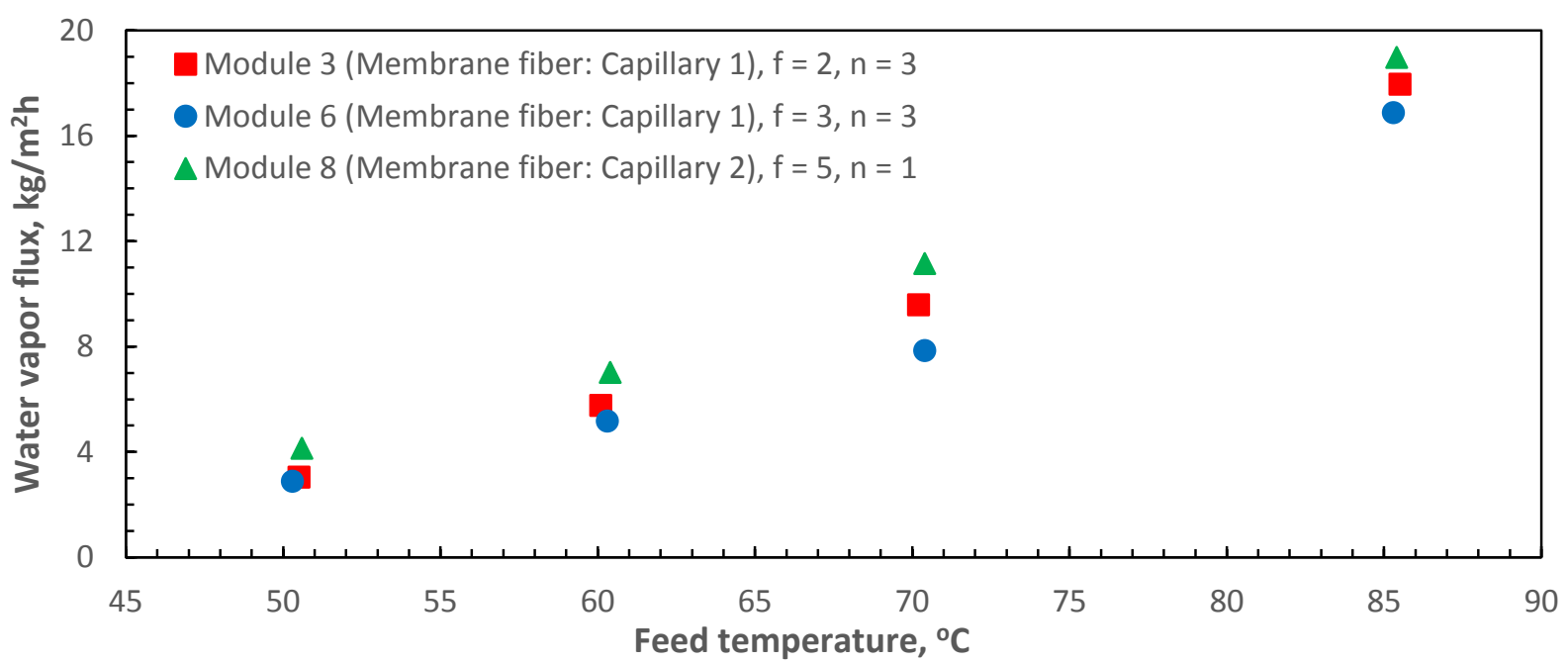

545

546

547

548 549

550

Figure 13. Effect of membrane fiber type on water vapor flux at different feed temperatures. Modules: 3, 6 and 8; $\mathrm{f}$ is the number of membrane fibers per shell; $\mathrm{n}$ is the number of condenser fibers per membrane fiber. Coolant temperature: $18^{\circ} \mathrm{C}$; feed flow rate: $1,100 \mathrm{~mL} / \mathrm{min}$; coolant flow rate: $280 \mathrm{~mL} / \mathrm{min}$.

This study was focused on the development and performance evaluation of the co-axial hollow fiber AGMD modules for seawater desalination. Given the promising results obtained in this study, future work will be focused on scaling-up the module to explore its commercialization potential. Therefore, a range of important parameters needs to be addressed including the pressure drop through various module passages (which would be more pronounced as compared to the lab-scale modules due to the increased module length), permeate condensation regimes/rates, temperature polarization, and the module length or number of stages effect [49]. As shown in our study, permeate bridging and flooding effects aversively effected the system's performance. One possible way to improve the permeate flux and avoid bridging/flooding inside the module is to apply vacuum to the permeate collection port. As such, the water vapor will instantaneously be evacuated from the permeate compartment thereby in-module vapor condensation and hence permeate flow obstruction would be minimized. Moreover, a comprehensive numerical performance simulations will also be conducted to determine the effect of module length and operating parameters on the 
heat and mass transfer inside the full-scale modules. This will allow to design and manufacture the optimal module configuration aiming to attain high permeate flux and thermal efficiency.

\section{Conclusions}

In this study, we developed and comprehensively exanimated a novel AGMD module which combined hollow fiber membranes and hollow fiber condensers (heat exchangers) concealed into cylindrical shell. In this module, hollow fiber condensers were inserted inside the hollow fiber membranes offering a more compact and better internal heat recovery module. The water vapor condensation occurred in the free space between the outer wall of condenser fibers and inner wall of membrane fibers. We evaluated the effect of condenser fiber number $(n=1 \div 4)$ on process performance at different operating parameters with respect to desalination of Red Sea water. We found that at high feed temperatures of $70^{\circ} \mathrm{C}$ and $85^{\circ} \mathrm{C}$, the vapor flux increased with increasing the number of condenser fibers up to $n=3$ and then decreased when $n$ was further increased to 4 due to the deficiency of the free condensation area inside the membrane fiber lumen (dropwise condensation type). This effect was less pronounced at low feed temperatures of $50^{\circ} \mathrm{C}$ and $60^{\circ} \mathrm{C}$ due to low vapor fluxes. The increase in the feed flow rate positively affected the vapor fluxes across the membrane fiber to higher extent as compared to the increase in coolant flow rate. The highest vapor flux of $20 \mathrm{~kg} / \mathrm{m}^{2} \mathrm{~h}$ was achieved at a feed temperature of $85^{\circ} \mathrm{C}$, feed flow rate of $1,100 \mathrm{~mL} / \mathrm{min}$ and coolant flow rate of $1,000 \mathrm{~mL} / \mathrm{min}$. The packing density of membrane fibers inside the shell also influenced the process performance. A correlation between the fiber wall thickness and vapor fluxes was observed, and higher vapor fluxes were achieved in the case when AGMD modules were packed with capillary membrane fibers (thinner walls) as compared to modules packed with tubular membranes (thicker walls).

\section{$\underline{\text { Acknowledgements }}$}

The research reported in this paper was supported by King Abdullah University of Science and Technology [42], Saudi Arabia. The authors acknowledge help, assistance and support from the Water Desalination and Reuse Center (WDRC) staff.

\section{References}


[1] N. Ghaffour, J. Bundschuh, H. Mahmoudi, M.F.A. Goosen, Renewable energy-driven desalination technologies: A comprehensive review on challenges and potential applications of integrated systems, Desalination, 356 (2015) 94-114.

[2] J.-G. Lee, A.S. Alsaadi, A.M. Karam, L. Francis, S. Soukane, N. Ghaffour, Total water production capacity inversion phenomenon in multi-stage direct contact membrane distillation: A theoretical study, Journal of Membrane Science, 544 (2017) 126-134.

[3] M. Elimelech, W.A. Phillip, The Future of Seawater Desalination: Energy, Technology, and the Environment, Science, 333 (2011) 712-717.

[4] A. Boubakri, S.A.-T. Bouguecha, I. Dhaouadi, A. Hafiane, Effect of operating parameters on boron removal from seawater using membrane distillation process, Desalination, 373 (2015) 86-93.

[5] P. Pal, A.K. Manna, Removal of arsenic from contaminated groundwater by solar-driven membrane distillation using three different commercial membranes, Water Research, 44 (2010) 5750-5760.

[6] E. Curcio, G.D. Profio, E. Fontananova, E. Drioli, 13 - Membrane technologies for seawater desalination and brackish water treatment, in: Advances in Membrane Technologies for Water Treatment, Woodhead Publishing, Oxford, 2015, pp. 411-441.

[7] P. Wang, T.-S. Chung, Recent advances in membrane distillation processes: Membrane development, configuration design and application exploring, Journal of Membrane Science, 474 (2015) 39-56.

[8] L. Francis, N. Ghaffour, A.S. Alsaadi, G.L. Amy, Fabrication and characterization of functionally graded Poly(vinylidine fluoride)-silver nanocomposite hollow fibers for sustainable water recovery, Science of Advanced Materials 6 (2014) 2659-2665.

[9] E. Drioli, A. Ali, F. Macedonio, Membrane distillation: Recent developments and perspectives, Desalination, 356 (2015) 56-84.

[10] J. Koschikowski, M. Wieghaus, M. Rommel, V.S. Ortin, B.P. Suarez, J.R. Betancort Rodríguez, Experimental investigations on solar driven stand-alone membrane distillation systems for remote areas, Desalination, 248 (2009) 125-131.

[11] W. Arras, N. Ghaffour, A. Hamou, Performance evaluation of BWRO desalination plant - A case study, Desalination 235 (2009) 170-178.

[12] J. Redondo, M. Busch, J.-P. De Witte, Boron removal from seawater using FILMTEC high rejection SWRO membranes, Desalination, 156 (2003) 229-238.

[13] A.D. Khawaji, I.K. Kutubkhanah, J.-M. Wie, Advances in seawater desalination technologies, Desalination, 221 (2008) 47-69.

[14] D. Hou, G. Dai, J. Wang, H. Fan, Z. Luan, C. Fu, Boron removal and desalination from seawater by PVDF flat-sheet membrane through direct contact membrane distillation, Desalination, 326 (2013) 115124.

[15] J. Bundschuh, N. Ghaffour, H. Mahmoudi, M. Goosen, S. Mushtaq, J. Hoinkis, Low-cost low-enthalpy geothermal heat for freshwater production: Innovative applications using thermal desalination processes, Renewable and Sustainable Energy Reviews, 43 (2015) 196-206.

[16] A. Chafidz, E.D. Kerme, I. Wazeer, Y. Khalid, A. Ajbar, S.M. Al-Zahrani, Design and fabrication of a portable and hybrid solar-powered membrane distillation system, Journal of Cleaner Production, 133 (2016) 631-647.

[17] N. Ghaffour, V.K. Reddy, M. Abu-Arabi, Technology development and application of solar energy in desalination: MEDRC contribution, Renewable and Sustainable Energy Reviews 15 (2011) 4410- 4415.

[18] S. Shukla, J.P. Méricq, M.P. Belleville, N. Hengl, N.E. Benes, I. Vankelecom, J. Sanchez Marcano, Process intensification by coupling the Joule effect with pervaporation and sweeping gas membrane distillation, Journal of Membrane Science, 545 (2018) 150-157.

[19] L. Francis, N. Ghaffour, A.A. Alsaadi, G.L. Amy, Material gap membrane distillation: A new design for water vapor flux enhancement, Journal of Membrane Science, 448 (2013) 240-247.

[20] A.S. Alsaadi, A. Alpatova, J.-G. Lee, L. Francis, N. Ghaffour, Flashed-feed VMD configuration as a novel method for eliminating temperature polarization effect and enhancing water vapor flux, Journal of Membrane Science 563 (2018) 175-182. 
[21] R. Tian, H. Gao, X.H. Yang, S.Y. Yan, S. Li, A new enhancement technique on air gap membrane distillation, Desalination, 332 (2014) 52-59.

[22] S.R. Krajewski, W. Kujawski, M. Bukowska, C. Picard, A. Larbot, Application of fluoroalkylsilanes (FAS) grafted ceramic membranes in membrane distillation process of $\mathrm{NaCl}$ solutions, Journal of Membrane Science, 281 (2006) 253-259.

[23] A. Alpatova, A. Alsaadi, N. Ghaffour, Boron evaporation in thermally-driven seawater desalination: Effect of temperature and operating conditions, Journal of Hazardous Materials 351 (2018) 224-231.

[24] A.S. Jönsson, R. Wimmerstedt, A.C. Harrysson, Membrane distillation - a theoretical study of evaporation through microporous membranes, Desalination, 56 (1985) 237-249.

[25] A. Alsaadi, L. Francis, H. Maab, G. Amy, N. Ghaffour, Evaluation of air gap membrane distillation process running under sub-atmospheric conditions: Experimental and simulation studies, Journal of Membrane Science, 489 (2015) 73-80.

[26] L.-H. Cheng, P.-C. Wu, J. Chen, Modeling and optimization of hollow fiber DCMD module for desalination, Journal of Membrane Science, 318 (2008) 154-166.

[27] L.-H. Cheng, P.-C. Wu, J. Chen, Numerical Simulation and Optimal Design of AGMD-Based Hollow Fiber Modules for Desalination, Industrial \& Engineering Chemistry Research, 48 (2009) 4948-4959.

[28] D. Singh, K.K. Sirkar, Desalination by air gap membrane distillation using a two hollow-fiber-set membrane module, Journal of Membrane Science, $421-422$ (2012) 172-179.

[29] K. Yao, Y. Qin, Y. Yuan, L. Liu, F. He, Y. Wu, A continuous-effect membrane distillation process based on hollow fiber AGMD module with internal latent-heat recovery, AIChE Journal, 59 (2013) 12781297.

[30] H. Geng, H. Wu, P. Li, Q. He, Study on a new air-gap membrane distillation module for desalination, Desalination, 334 (2014) 29-38.

[31] L.-H. Cheng, Y.-H. Lin, J. Chen, Enhanced air gap membrane desalination by novel finned tubular membrane modules, Journal of Membrane Science, 378 (2011) 398-406.

[32] R. Aryapratama, H. Koo, S. Jeong, S. Lee, Performance evaluation of hollow fiber air gap membrane distillation module with multiple cooling channels, Desalination, 385 (2016) 58-68.

[33] D. Papini, A. Cammi, Modelling of Heat Transfer Phenomena for Vertical and Horizontal Configurations of In-Pool Condensers and Comparison with Experimental Findings, Science and Technology of Nuclear Installations, 2010 (2010).

[34] L.E. Herranz, J.L. Muñoz-Cobo, G. Verdu, Heat transfer modeling in the vertical tubes of the passive containment cooling system of the simplified boiling water reactor, Nuclear Engineering and Design, 178 (1997) 29-44.

[35] S.-Z. Kuhn, V. Schrock, P. Peterson, An investigation of condensation from steam-gas mixtures flowing downward inside a vertical tube, in, Nuclear Regulatory Commission, Washington, DC (United States), 1995.

[36] H.C. No, H.S. Park, Non-iterative condensation modeling for steam condensation with noncondensable gas in a vertical tube, International Journal of Heat and Mass Transfer, 45 (2002) 845-854.

[37] D. Labuntsov, Heat transfer in film condensation of pure steam on vertical surfaces and horizontal tubes, Teploenergetika, 4 (1957) 72-79.

[38] S.J. Kim, H.C. No, Turbulent film condensation of high pressure steam in a vertical tube, International Journal of Heat and Mass Transfer, 43 (2000) 4031-4042.

[39] B.J. Zhang, C. Kuok, K.J. Kim, T. Hwang, H. Yoon, Dropwise steam condensation on various hydrophobic surfaces: Polyphenylene sulfide (PPS), polytetrafluoroethylene (PTFE), and self-assembled micro/nano silver (SAMS), International Journal of Heat and Mass Transfer, 89 (2015) 353-358.

[40] M.R. Rajkumar, A. Praveen, R.A. Krishnan, L.G. Asirvatham, S. Wongwises, Experimental study of condensation heat transfer on hydrophobic vertical tube, International Journal of Heat and Mass Transfer, 120 (2018) 305-315.

[41] M.S. El-Bourawi, Z. Ding, R. Ma, M. Khayet, A framework for better understanding membrane distillation separation process, Journal of Membrane Science, 285 (2006) 4-29. 
694 [42] D.M. Warsinger, J. Swaminathan, L.L. Morales, J.H. Lienhard V, Comprehensive 695 condensation flow regimes in air gap membrane distillation: Visualization and energy efficiency, 696 Journal of Membrane Science, 555 (2018) 517-528.

697 [43] I. Hitsov, K. De Sitter, C. Dotremont, P. Cauwenberg, I. Nopens, Full-scale validated Air

698 Gap Membrane Distillation (AGMD) model without calibration parameters, Journal of 699 Membrane Science, 533 (2017) 309-320.

700 [44] L. Eykens, I. Hitsov, K. De Sitter, C. Dotremont, L. Pinoy, B. Van der Bruggen, Direct 701 contact and air gap membrane distillation: Differences and similarities between lab and pilot 702 scale, Desalination, 422 (2017) 91-100.

703 [45] J. Swaminathan, H.W. Chung, D.M. Warsinger, J.H. Lienhard V, Energy efficiency of 704 membrane distillation up to high salinity: Evaluating critical system size and optimal membrane 705 thickness, Applied Energy, 211 (2018) 715-734.

706 [46] S. Soukane, M.W. Naceur, L. Francis, A. Alsaadi, N. Ghaffour, Effect of feed flow pattern on the 707 distribution of permeate fluxes in desalination by direct contact membrane distillation, Desalination, 418 708 (2017) 43-59.

709 [47] L. Cheng, Y. Zhao, P. Li, W. Li, F. Wang, Comparative study of air gap and permeate gap membrane 710 distillation using internal heat recovery hollow fiber membrane module, Desalination, 426 (2018) 42-49.

711 [48] Water Treatment: Principles and Design, John Willey \& Sons, Inc, Hoboken, USA, 2005.

712 [49] S. Soukane, J.-G. Lee, N. Ghaffour, Direct contact membrane distillation module scale-up calculations: 713 Choosing between convective and conjugate approaches, Separation and Purification Technology 209 714 (2019) 279-292.

715

716 